\title{
IMPROVED RECOVERY FROM GULF OF MEXICO RESERVOIRS
}

Grant Number: DE-FG22-95BC14802

Louisiana State University

Department of Petroleum Engineering

Baton Rouge, LA 70803-6417

5

\author{
Award Date: February 14, 1995 \\ Anticipated Completion Date: August 13, 1995 \\ Total Government Award: \$1,266,667.00 \\ Principal Investigator: W. Clay Kimbrell \\ Zaki A. Bassiouni \\ Adam T. Bourgoyne
}

Contracting Officer's Representative: Edith C. Allison

Quarterly Status Report: Covering October 1, 1995 - December 31, 1995

Report Date: January 31, 1996

\section{DISCLAIMER}

This report was prepared as an account of work sponsored by an agency of the United States Government. Neither the United States Government nor any agency thereof, nor any of their employees, makes any warranty, express or implied, or assumes any legal liability or responsibility for the accuracy, completeness, or usefulness of any information, apparatus, product, or process disclosed, or represents that its use would not infringe privately owned rights. Reference herein to any specific commercial product; process, or service by trade name, trademark, manufacturer, or otherwise does not necessarily constitute or imply its endorsement, recommendation, or favoring by the United States Government or any agency thereof. The views and opinions of authors expressed herein do not necessarily state or reflect those of the United States Government or any agency thereof.

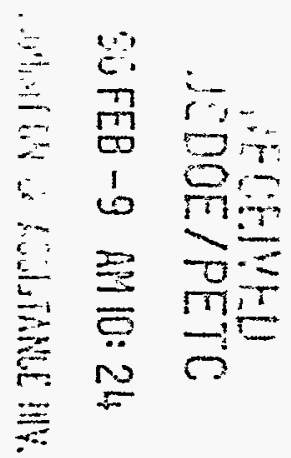

US/DOE Patent Clearance is not required prior to publication of this document. 


\section{OBJECTIVE}

Oil imports have again risen to an alarming level, causing balance of trade deficits that threaten our long-term economic strength and our future position of world leadership. The domestic oil and gas industry has been greatly weakened by a decade of low oil and gas prices, and further declines in domestic oil and gas production appear certain. The nation must address this problem or suffer consequences that potentially threaten our energy independence.

The Gulf of Mexico Basin offers the greatest near-term potential for reducing the future decline in domestic oil and gas production. The Basin is less mature than productive on-shore areas, large unexplored areas remain, and there is great potential for reducing bypassed oil in known fields. The political climate in the states bordering the central and western Gulf of Mexico areas remains favorable for oil and gas exploration, in contrast to regions where there is a moratorium on drilling. Finally, operating costs are lower in the Gulfof Mexico than in frontier areas such as Alaska.

Much of the remaining oil in the offshore is trapped in formations that are extremely complex due to intrusions of salt domes. In addition, over 36,000 square miles of largely unexplored sediments in the central Gulf of Mexico are below sheet-like salt structures. Conventional seismic processing techniques cannot clearly image near or below salt, therefore, substantial volumes of oil may have remained uncontacted by previous drilling. Recently, however, significant innovations have been made in seismic processing and reservoir simulation. In addition, significant advances have been made in deviated and horizontal drilling technologies. Effective application of these technologies along with improved integrated resource management method's offer opportunities to significantly increase Gulf of Mexico production, delay platform abandonments, and preserve access to a substantial remaining oil target for both exploratory drilling and advanced recovery processes.

On February 18, 1992, Louisiana State University (the Prime Contractor) with two technical subcontractors, BDM, Inc. and ICF, Inc., began a research program to estimate the potential oil and gas reserve additions that could result from the application of advanced secondary and enhanced oil recovery technologies and the exploitation of undeveloped and attic oil zones in the Gulf of Mexico oil fields that are related to piercement salt domes.

This project is a one year continuation of this research and will continue work in reserooir description, extraction processes, and technology transfer. Detailed data will be collected for two previously studied reservoirs: a South Marsh Island reservoir operated by Taylor Energy and one additional Gulf of Mexico reservoir operated by Mobil. Additional reservoirs identified during the project will also be studied if possible. Data collected will include reprocessed 2-D seismic data, newly acquired 3-D data, fluid data, fluid samples, pressure data, well test data, well logs, and core data/samples. The new data will be used to refine reservoir and geologic characterization of these reservoirs. Further laboratory investigation will provide additional simulation input data in the form of PVT properties, relative permeabilities, capillary pressures, and water compatibility. Geological investigations will be conducted to refine the models of mud-rich submarine fan architectures used by seismic analysts and reservoir engineers. Research on advanced reservoir simulation will also be conducted.

The research effort is being conducted in four major areas:

I. Reservoir Characterization Research

II. Extraction Research - Simulation of Extraction Processes

III. Extraction Research - Improved Oil Recovery

IV. Technology Transfer Activities

\section{SUMMARY OF TECHNICAL PROGRESS}

\section{Reservoir Characterization Research}

The Sun Sparc 20 and Silicon Graphics Indigo 2 workstations have been successfully installed and set-up. These tasks did not progress as expected due to hardware problems with the Sun Sparc20 workstation. Portions of the system had to be replaced due to damaged boards on the initial delivery. However, both systems have now been successfully set-up and are working properly. Following the hardware set-up, an attempt was made to load the Landmark software. 
However, upon installation, unexpected licensing problems occurred which again delayed the progress of the project. The licensing problem has now been resolved and the software is currently being installed. The loading of the 3-D seismic will follow the successful installment of the Landmark software. All other aspects of the project are continuing as expected.

Also, additional information has been obtained from Mobil to upgrade and modify characterization and simulation of the reservoir which they operate.

\section{Extraction Research - Simulation of Extraction Processes}

The finite element method (FEM) well-block has been interfaced with the BOAST program and results are being obtained that are consistent with reservoir engineering. We have obtained these results by using data furnished by NIPER. After a period of time, our FEM wellblock exhibits oscillations that need to be eliminated. Our work toward eliminating the oscillations in our finite element 3-D 3-phase oil/water/gas flow simulator is addressing the possible causes. The possible causes being investigated are:

- Numerical and caused by globally ill-conditioned matrices,

- Improper specifications of the boundary conditions at the well which cause spurious reflections,

- Lack of enough dissipation of our numerical scheme, that is which cause spurious reflections,

- Lack of enough dissipation of our numerical scheme, that is mesh refinement in the vicinity of the oil/water/gas fronts and near the well is not sufficient to eliminate the oscillations.

The mesh refinement required in our 1-D and 2-D problems was considerable, and we suspect that even more will be required for the 3-D problem. We have developed automatic grid refinement code that is being tested. Testing in 2-D is completed, but in 3-D this testing is difficult and very complicated. Once this testing is completed and our grid is refined, our matrices will become very large. The possibility of an ill-conditioned matrix is being studied with subroutines that determine the largest and smallest eigen-values. The eigen-value subroutines are currently being added to the BOAST-FEM model. The specification of the boundary conditions at the well is a problem that is very active at this time with several research papers appearing now. We are studying these and will determine if they will eliminate our problem. We are also studying the non-convexity of fractional fluid flow, where our oscillations begin after the breakthrough of a second phase.

Experimentation with the three datasets furnished by NIPER continues. Of the three reservoir datasets furnished, only two have been used in our experiments to date. The original dataset used in testing of our BOAST-FEM model has a single layer and is a 3-D, 2-phase oil/gas situation. We have used this data to test the FEM equations that were developed for this problem. These FEM equations were modified as necessary to describe the 3-D, 3-phase flow in the well-block. The second dataset required modification of our BOAST-FEM model to accommodate more than one layer. This has been successfully completed. In fact, the test data has a gas injection well and a production well that produces from the deepest layer with no production from the top layers. The originally derived FEM flow equations have been modified to better model the gravity effect. We solve for free gas, $\mathrm{Sg}, \mathrm{Sw}$, and Po implicitly. 
Future work will include visual presentation of some of the output, experimentation with iterative solvers, continued work on the cause of the oscillations, and testing on other reservoir problems. We are currently preparing a manuscript for publication and are currently investigating our technique for dynamically refining local regions of the mesh during simulations. It should be noted that this will be difficult. Thus, we are also beginning to experiment with higher-order elements, believing these will produce more accurate solutions without requiring as much mesh refinement. The end result of this work will probably use a combination of mesh-refinement and higher order elements.

\section{Extraction Research - Improved Oil Recovery}

In the attic oil recovery process, gas is injected into the highest well in the reservoir. The gas migrates upstructure, forming a gas cap or contributing to a gas cap already present. The gas displaces oil from the upper portion of the reservoir, lowering the oil-water contact.

\section{Experimental Materials}

In the laboratory we modeled the attic oil recovery process by using a sand pack. Ottawa sand was packed in a core holder for an effective porosity of $33 \%$. The core holder is $9.5 \mathrm{ft}$ long and $0.25 \mathrm{ft}$ in diameter. It is rated for $10,000 \mathrm{psi}$ and was fitted with injection ports to allow for the physical simulation of the attic oil recovery process.

Deoxygenated distilled water was used in the apparatus to avoid rusting of the core during the long soak periods. Crude oil from the South Marsh Island, B-65G reservoir was obtained and its properties measured. A series of experiments are planned using different gases. The projected time line and the number of cycles is shown in the following table.

$\begin{array}{llll}\text { Expt No } & \begin{array}{c}\text { Approximate } \\ \text { Start Date }\end{array} & \text { No of Cycles } & \text { Gas to Use } \\ 1 & & & \text { Methane } \\ 2 & \text { In progress } & 3 & \text { Methane } \\ 3 & 2 / 12 / 96 & 3 & \text { Nitrogen } \\ 4 & 3 / 11 / 96 & 2 & \text { Nitrogen } \\ 5 & 3 / 25 / 96 & 2 & \text { Carbon dioxide and Methane } \\ 6 & 4 / 15 / 96 & 3 & \text { Carbon dioxide and Nitrogen }\end{array}$

The properties of the crude oil and the experimental conditions to be used for these experiments are listed below.

\begin{tabular}{lll} 
Expt. Pressure (psi) & 3100 \\
Expt. Temperature (F) & \multicolumn{2}{c}{144} \\
API 60/60 & \multicolumn{2}{c}{31.5} \\
Density (g/cc) @24C & 0.856 & \\
@65C & 0.820 \\
Viscosity (cp) @24C & 12.37 \\
@65C & 3.76 & \\
Asphaltene (wt\%) & \multicolumn{2}{c}{0.5023}
\end{tabular}


Although this crude oil has a low asphaltene content, a small portion of it does not dissolve easily in the solvents used for core/sandpack cleaning. This oil should not be used in the consolidated cores due to probable plugging problems.

The asphaltene content of two other crude oils was determined. Both are light oils that have similar properties to the South Marsh Island 73 crude oil and could be used as substitutes if necessary.

Name Asphaltene (wt \%) Density

Paradis, Texaco

0.7035

0.831

W. Hackberry, Amoco

0.5002

0.870

\section{Experimental Procedure}

Ruska positive displacement pumps are to be used for injecting water and oil. Gas will be injected using a ruska positive displacement mercury pump. Pressures at the upstream and downstream ends are monitored by digital meters. An automatic back pressure regulator is used to maintain the core at a constant pressure.

The core is initially saturated with oil injected from the top of the core for a uniform and gravity stable displacement. Water is then pumped from the bottom of the core and produced from the center port. Thus, only residual oil remains below the center port while the oil above this port is still at the initial oil saturation. The core is allowed to stabilize for a day and then gas is injected into the center port which is also used to produce the oil. This simulated a single well reservoir where the same well is used to produce oil and inject gas. After gas injection the core is left to soak. Then it is water flooded from the bottom of the core and oil is produced from the center.

\section{$\underline{\text { Technology Transfer }}$}

There was no technology transfer during this quarter.

\section{REFERENCES}

There were no references during this quarter. 